\title{
No limiar da escrita argumentativa: um estudo exploratório
}

\author{
Ana Luísa Costa \\ Escola Superior de Educação do Instituto Politécnico de Setúbal \\ e Centro de Linguística da Universidade de Lisboa
}

\begin{abstract}
:
The aim of this paper is to contribute with some empirical evidence to the study of the development of argumentative writing. Curricular documents and Portuguese syllabi over the past 30 years have neglected argumentative writing, as the writing of personal opinion texts in the $1^{\text {st }}$ cycle of Basic Education. Although some literature on writing development conceives argumentative writing as a late skill, some research on argumentative writing development brings into debate the importance of promoting writing skills within different textual genres, specifically with argumentative texts, in order to improve linguistic literacy and increase writing skills.
\end{abstract}

Keywords: writing, genre, textual awareness, personal opinion text, argumentative essay

Palavras-chave: escrita, géneros textuais, consciência textual, texto de opinião, texto argumentativo

\section{Introdução}

$\mathrm{Na}$ literatura sobre aquisição da escrita, diferentes modelos teóricos (Ferreiro e Teberosky, 2009; Nicholls et al., 1989) permitem caracterizar estádios de desenvolvimento anteriores à emergência da escrita compositiva, fase que surge, geralmente, por volta do segundo ano de escolarização (Martins e Niza, 1998). Relativamente a esta fase da escrita de textos, não é fácil encontrar estudos que se centrem nas suas características específicas, assumindo-se que se trata mais de um ponto de chegada - conseguir compor um texto - do que da fase inicial de uma competência que se desenvolve ao longo de, pelo menos, todo o processo de escolarização. Paralelamente, no currículo de escrita preconizado pelos documentos orientadores do ensino da língua materna para os primeiros anos de escolaridade, encontram-se algumas discrepâncias que não ajudam a clarificar nem o que se espera dos desempenhos dos jovens aprendentes de escrita, nem do percurso educativo a seguir para um desenvolvimento equilibrado desta competência. $\mathrm{O}$ presente trabalho, enquadrado em investigação em linguística educacional, tem por base um 
estudo exploratório desenvolvido com o objetivo de obter dados empíricos, com base em produções escritas de crianças, que contribuam para um melhor conhecimento das capacidades de escrita evidenciadas no limiar da escrita compositiva, com particular enfoque na escrita argumentativa.

A ideia de que há géneros textuais mais fáceis de dominar, como o relato ou a narrativa, e outros mais difíceis, requerendo capacidades mais complexas, como o explicativo ou o argumentativo, deixa em aberto um problema no estabelecimento de uma didática da escrita: o ensino da escrita deve visar primeiro géneros menos complexos, começando-se pela escrita de narrativas, introduzindo apenas mais tarde a escrita de outros géneros? $\mathrm{Ou}$, pelo contrário, o desenvolvimento equilibrado da competência de escrita requer o uso da escrita com fins diversificados, recorrendo a diferentes produtos textuais num percurso de complexidade crescente para cada género? Neste âmbito, assume-se como questão enquadradora do presente estudo a que se enuncia em (1):

(1) A escrita argumentativa deve ser trabalhada desde a emergência da escrita compositiva?

Esta questão tem sido objeto de reflexão em alguns trabalhos sobre desenvolvimento das capacidades argumentativas em diferentes línguas, como, por exemplo, para o francês, no estudo de Brassart (1990), sobre o desenvolvimento de capacidades discursivas de crianças entre os 8 e os 12 anos, e para o português do Brasil, no trabalho de Leal e Morais (2006), com crianças da mesma faixa etária a frequentar entre a segunda e a quarta série. Tendo por referência as questões em análise em estudos como os referidos, a primeira questão, mais geral, foi desdobrada em duas questões específicas de didática da escrita, formuladas em (2) e em (3).

(2) Na elaboração de metas, programas e planificações para as turmas, devem trabalhar-se primeiro géneros mais simples e só mais tarde géneros mais complexos ou a consciência textual e discursiva dos diferentes padrões de escrita deve ser estimulada, de forma equilibrada, desde a emergência da escrita compositiva? 
Para serem capazes de produzir enunciados argumentativos, os alunos têm de ter disponíveis competências textuais, como a consciência do modelo de texto, e recursos linguísticos, como nexos causais, condicionais e contrastivos (Costa, 2010, 2015; Flamenco García, 1999). Assim, para se saber se podemos pôr os alunos a escrever textos de caráter argumentativo, é necessário saber se as estruturas linguísticas prototípicas dos enunciados argumentativos estão disponíveis na gramática, entendida como conhecimento implícito do aluno. Por esta razão, formula-se a questão em (3).

(3) Que competências linguísticas e textuais necessárias à argumentação estão em desenvolvimento no $1 .^{\circ}$ ciclo do ensino básico?

Para uma melhor compreensão do estado da arte quanto a escrita de textos de carácter argumentativo no currículo de língua materna, no ponto 2., procede-se a uma análise dos programas e metas posteriores à Reforma Educativa de 1986. No ponto 3., apresentam-se alguns dados sobre capacidades argumentativas nos primeiros anos de escolaridade, decorrentes de estudos em outros sistemas educativos. O quarto ponto integra o estudo exploratório desenvolvido, explicitando-se as suas limitações, o seu desenho experimental e a análise de resultados, que sustenta as considerações finais do ponto 5 .

\section{A escrita argumentativa no currículo de língua materna}

Da leitura cruzada dos documentos curriculares do ensino do português nos últimos trinta anos, entre 1986 e 2016, considerando-se especificamente as prescrições para a expressão escrita e as referências a discurso argumentativo, parece que se pode inferir uma assunção tácita de que a escrita de textos de carácter argumentativo deve ser introduzida tardiamente no currículo (DGEBS, 1991; DEB, 2001; DGIDC, 2009; DGE, 2012; DGE, 2015).

No documento atualmente em vigor, o Programa e Metas Curriculares de Português do Ensino Básico (DGE, 2015), não se prevê a escrita de qualquer texto de carácter argumentativo, senão no $2 .^{\circ}$ ciclo do ensino básico, a partir do $5 .^{\circ}$ ano. No programa para este nível de ensino, 
nos conteúdos de «produção de texto», encontram-se os «géneros escolares: texto de características expositivas e texto de opinião» (p. 22). A meta correspondente a este conteúdo indica que os alunos, no final do $5 .^{\circ}$ ano, devem «escrever textos de opinião». Em (4) e em (5), transcrevem-se os descritores de desempenho esperados para esta meta no $5 .^{\circ}$ e no $6 .^{\circ}$ ano, respetivamente.

(4) «Escrever textos com a tomada de uma posição e apresentando, pelo menos, duas razões que a justifiquem e uma conclusão coerente». (p. 66)

(5) «Escrever textos com a tomada de uma posição, a apresentação de, pelo menos, três razões que a justifiquem, com uma explicação dessas razões, e uma conclusão coerente». (p. 71)

$\mathrm{Na}$ estruturação do texto de opinião, consideram-se elementos fundamentais (i) a tomada de posição, ou seja, uma tese, ainda que incipiente, (ii) a apresentação de razões, i.e., uma iniciação à formulação de argumentos e (iii) uma conclusão coerente. A progressão da capacidade de escrita argumentativa manifestar-se-á no aumento do número de razões-argumentos e na explicação dessas razões. Já no ciclo seguinte, no programa do 7..$^{\circ}$ ano, a progressão é evidenciada pela referência, na produção escrita, a «texto de características argumentativas», entre os géneros escolares de complexidade crescente (p. 30).

A ausência de conteúdos e metas para a escrita argumentativa antes do $5 .^{\circ}$ ano de escolaridade podia levar a crer que se supõe não haver consciência linguística e textual que suporte tais aprendizagens. Todavia, a consulta dos conteúdos previstos para o domínio da oralidade revela que, no domínio do oral formal, se prevê a capacidade de argumentar logo desde o $3 .^{\circ}$ ano do $1 .^{\circ}$ ciclo. Neste nível de ensino, para o conteúdo «produção de discurso oral», os alunos são introduzidos nos géneros escolares, devendo ser capazes de produzir um «pequeno discurso persuasivo» (p. 13); ainda no $1 .^{\circ}$ ciclo, no 4. ${ }^{\circ}$ ano, devem também participar no «debate de ideias» (p. 16). Embora se assuma no atual Programa e Metas uma emergência precoce da escrita compositiva, entendida como a capacidade de compor unidades textuais, uma vez que se prevê a escrita de «pequenos textos» (p. 10) logo no 1. ${ }^{\circ}$ ano e de «pequenas narrativas» (p. 12) no 
2. ${ }^{\circ}$, não se concebe que as competências inerentes ao discurso argumentativo oral possam ser mobilizadas para o discurso escrito.

Se a escrita de textos de opinião só deve ser iniciada ao fim de cinco anos de escolarização segundo as Metas Curriculares (DGE, 2012, pp. 30-31 e p. 39; 2015, p. 66 e p. 71), esta orientação representa uma antecipação deste conteúdo em relação as orientações curriculares mais antigas. Na verdade, a ausência de orientações curriculares para a escrita de texto de opinião no 1. ${ }^{\circ}$ ciclo é uma herança de longa data: nos Programas de Língua Portuguesa para o Ensino Básico, publicados no início dos anos 90, só há referência, na «escrita para apropriação de técnicas e de modelos», a «texto de opinião» no $8^{\circ}$ ano (DGEBS, 1991, p. 45). Para esclarecimento dos níveis de desempenho propostos no Currículo Nacional do Ensino Básico para a «expressão escrita» (DEB, 2001, p. 35), a consulta de A Língua Materna na Educação Básica esclarece que o referencial para a escrita prevê para o $1 .^{\circ}$ ciclo apenas «escrita para relato» e, mesmo no $3 .^{\circ}$ ciclo, os modelos de escrita orientada são «texto narrativo, descritivo e expositivo» (Sim-Sim, Duarte e Ferraz, 1997, p. 82).

Nos Programas de Português, documento que só esteve em vigor durante seis anos, entre 2009 e 2015, tal como nos restantes textos curriculares mencionados, também não se prescreve a escrita de texto de carácter argumentativo no $1 .^{\circ}$ ciclo do ensino básico. É neste documento que a escrita de texto de opinião é antecipada para o $2 .^{\circ}$ ciclo, aparecendo como conteúdo relativo a «escrever para construir e expressar conhecimentos» (DGIDC, 2009, p. 89).

Em suma, os documentos orientadores do ensino da língua materna nos últimos trinta anos são unânimes: as crianças não devem aprender a escrever a sua opinião antes do $2 .^{\circ}$ ciclo. Que razões fundamentaram estas opções teórico-didáticas?

\section{Alguns dados sobre escrita argumentativa nos primeiros anos de escolaridade}

Quando um professor do $1 .^{\circ}$ ciclo afirma que os seus alunos já sabem ler, pode estar a referirse a desempenhos de leitura tão distintos quanto a capacidade de decifrar palavras e frases, com verbalização oral do material escrito, ou a capacidade de manifestamente compreender, acedendo ao significado de palavras, frases e textos (Sim-Sim, 2007, 2009). Paralelamente, na iniciação à 
aprendizagem da escrita, é possível distinguir dois momentos cruciais: a emergência da competência gráfica e ortográfica e a emergência da competência compositiva, entendida como «a competência relativa à forma de combinar expressões linguísticas para formar um texto» (Barbeiro e Pereira, 2007, p. 7). Vários estudos têm confirmado a importância de um contacto precoce com a escrita, sendo possível estabelecer estádios de desenvolvimento por que passam as conceções das crianças sobre a linguagem escrita antes da iniciação da aprendizagem formal da leitura e da escrita (Ferreiro e Teberosky, 2009; Martins e Niza, 1998). Estes estádios de aquisição da escrita culminam na escrita ortográfica, ou seja, na capacidade de escrever palavras e frases em conformidade com a ortografia da língua-alvo. O interesse pelo desenvolvimento da escrita enquanto processo mental, em estudos de psicolinguística, contribuiu com dados sobre escrita para lá da dimensão ortográfica: propuseram-se representações teóricas do processo, através de modelos processuais de escrita (Hayes e Flower, 1980; Scardamalia e Bereiter, 1987; Grabe e Kaplan, 1996), e procurou-se caracterizar as fases de aprendizagem da escrita no início do seu ensino formal (Nicholls et al. 1989; Martins e Niza, 1998).

O modelo de Nicholls et al. (1989) parte de um estudo longitudinal, no qual se observam não só crianças, entre os 5 e os 9 anos, mas também a atuação de professores em contexto de sala de aula. Segundo os autores, a escrita desenvolve-se em dois eixos, com diferentes graus de incidência nas cinco fases identificadas: o eixo dos problemas concetuais de escrita, implicando a estruturação da informação na escrita, e o eixo dos problemas de realização gráfica e ortográfica da escrita. A primeira fase deste modelo coincide com a escrita de garatujas, formas parecidas com letras e algarismos, podendo ainda incluir desenhos; na segunda fase, as crianças produzem letras convencionais, agrupadas e separadas por espaço, que conseguem ler, mas não são legíveis por outros. Ainda no primeiro ano de aprendizagem formal da escrita, numa terceira fase, emerge a capacidade de organizar as palavras em frases e em unidades textuais muito simples. As características associadas à quarta fase permitem perceber o limiar da escrita compositiva: capacidade de planificar globalmente um texto, de relatar sequencialmente uma experiência vivida e de estruturar uma pequena narrativa, a par do recurso a conectores diferentes para ligar frases e da capacidade de usar mais corretamente o ponto final e outros sinais de pontuação. $\mathrm{Na}$ quinta e última fase, destaca-se uma maior capacidade de selecionar o modelo de texto em função 
do objetivo comunicativo, evidenciando-se a sensibilidade a tipos de texto diversos. Havendo esta referência à diversidade de modelos textuais, note-se, contudo, que são mencionadas narrativas, mas não há qualquer informação sobre a escrita argumentativa.

No mesmo sentido, atendendo a contextos educativos diversificados, como as experiências educativas de crianças bilingues, ou a adquirir o inglês como L2, ou com problemas diversos de desenvolvimento, Menyuk e Brisk (2005), que defendem a importância da introdução precoce da escrita para o desenvolvimento da literacia em geral (pp. 92-96), referem-se a uma escrita que designam como «académica», assente capacidades para além do relato ou do reconto de histórias, numa fase mais tardia, na «middle childhood» (pp. 149-154).

A ausência de referências à emergência de uma escrita argumentativa permite inferir as razões que fundamentam as opções curriculares que adiam a introdução da escrita argumentativa para ciclos de escolarização mais avançados (ponto 2), parecendo ser consensual que o domínio do texto argumentativo é mais tardio que o domínio do texto narrativo. Todavia, a inexistência de dados sobre a aprendizagem precoce da escrita argumentativa impede qualquer conclusão e várias hipóteses podem ser colocadas para explicar o desfasamento temporal entre narrativa e argumentação na escrita. Como afirma Brassart (1990, p. 39): «Rien ne permet d'affirmer que, si le texte argumentatif était 'enseigner' au même titre que le récit, ce décalage temporel persisterait».

A proposta de um modelo explicativo do processo de escrita com duas componentes, uma de «knowledge-telling»e outra de «knowledge-transforming» (Scardamalia e Bereiter, 1987a, 1987b), a primeira associada a escritores menos hábeis e a segunda a escritores mais proficientes, consegue dar conta quer de diferenças individuais, quer de diferentes perfis de um mesmo escritor em diferentes momentos. Tendo em consideração que o texto argumentativo constitui um género complexo, que exige um estilo de composição que não se limita a uma estruturação da informação sequencial ou cronológica, as tarefas que envolvem a escrita argumentativa constituem um problema retórico que requer a ativação do módulo de «transformação de conhecimento». Numa primeira aproximação ao modelo de Scardamalia e Bereiter (1987a; 1987b), pode fundamentar-se a hipótese de que a escrita argumentativa é uma tarefa mais complexa do que a escrita de narrativas, confirmando-se a ideia de que o ensino da escrita de 
textos de carácter argumentativo pode ser adiado para níveis de escolaridade mais avançados. No entanto, um trabalho experimental destes dois autores, com tarefas de escrita instrucional e de escrita de textos de opinião, evidencia a existência de diferentes abordagens de um mesmo problema de escrita ao longo do desenvolvimento desta competência. Efetivamente, tarefas com tópicos de escrita de opinião pessoal podem ser resolvidas através de estratégias de «knowledge telling» para a geração e estruturação de conteúdos textuais (Scardamalia e Bereiter, 1987b, p. 143), desde que o tema corresponda a um tópico familiar. Na escrita destes textos de opinião com temas conhecidos, os jovens escritores evidenciam algum domínio dos padrões retóricos semelhantes aos da persuasão na conversação oral, produzindo padrões de argumentação distintos dos modelos mais literários (Scardamalia e Bereiter, 1987a, p. 78). Esta ideia de que escritores mais e menos proficientes encontram diferentes soluções para fazer face a tarefas de escrita argumentativa deixa em aberto a possibilidade de se delinearem percursos escolares para $o$ desenvolvimento da escrita argumentativa. Assim, transpondo esta questão para o ensino da escrita, importa ter presente que é possível assumir como objetivo educacional a passagem de uma escrita de «relato de conhecimento» para uma escrita de «transformação de conhecimento»: «helping students to move from a knowledge-telling to a knowledge transforming approach to writing is an important and realistic educational objective» (Scardamalia e Bereiter, 1987b, p. 143). Nada indica que esta passagem se faça apenas no sentido dos géneros mais simples (como a narrativa) para os mais complexos (como a argumentação), e não, paralelamente, num percurso de desenvolvimento de estratégias progressivamente mais complexas e sofisticadas para enfrentar o problema retórico de um mesmo género (por exemplo, dentro dos géneros escolares, um percurso do texto de opinião sobre um tema familiar ao ensaio sobre uma obra).

Um dos aspetos estudados em Scardamalia e Bereiter (1987a, pp. 5-8) é a transferência de capacidades do discurso persuasivo conversacional oral para escrita de relato de conhecimento e, posteriormente, para a escrita de transformação de conhecimento. $O$ facto de que há capacidades argumentativas precoces na oralidade é consensual em vários estudos que abordam este tema, remontando esta capacidade a discurso produzido desde os 3-4 anos (Leal e Morais, 2006, p. 32). Além desta, outras ideias são comuns a diferentes estudos e propostas didáticas, destacando-se a constante observação de que (i) a argumentação escrita é mais complexa e só emerge após a 
escrita de narrativas, (ii) o domínio do texto argumentativo oferece dificuldades até a escritores mais experientes, adolescentes e adultos e (iii) o texto de carácter argumentativo é introduzido mais tarde nos currículos escolares de diferentes sistemas educativos. Reconhecendo estas assunções, alguns estudos, direcionados especificamente para o desenvolvimento de capacidades argumentativas, partem não só das características observadas nos desempenhos dos sujeitos, mas também das condições de aprendizagem formal da escrita para reequacionar as questões do desenvolvimento da argumentação escrita: será a escrita argumentativa inerentemente mais complexa ou as dificuldades observadas decorrerão de uma incidência menor no ensino da escrita de textos argumentativos? E, caso o domínio de padrões de escrita argumentativa seja, efetivamente, mais complexo, não beneficiará esta competência de intervenções educativas mais precoces? Será sustentável a defesa de que só se pode introduzir a escrita de texto de carácter argumentativo depois da emergência de estruturas linguísticas prototípicas do discurso argumentativo ou serão as práticas de escrita argumentativa ambientes naturalmente promotores do recurso a essas estruturas?

Com o objetivo de estudar o desenvolvimento do discurso argumentativo escrito em crianças dos 8 aos 12 anos, a frequentar entre o nível CE2 ${ }^{1}$ e o $5^{\text {e }}$, Brassart (1990) desenvolveu um estudo experimental com 156 alunos, envolvendo seis testes, introduzidos na planificação das turmas, para avaliar capacidades de produção escrita, resumo oral e compreensão de texto argumentativo. Do desenho experimental, com pré-teste e pós-teste aplicados a grupos de alunos organizados por níveis de ensino e idade, constou igualmente uma sequência de atividades de ensino explícito do texto argumentativo, não implementada num grupo de controlo. A análise dos resultados dos seis testes, tratados estatisticamente (idem, p. 36), tornou evidente a existência de desenvolvimento contínuo da escrita argumentativa desde os 7-8 anos, grupo dos alunos mais novos, e ao longo dos níveis de ensino envolvidos no estudo. Considerando os desempenhos dos estudantes nas provas de produção livre, de produção restrita e de resumo, foi possível identificar três grandes fases de desenvolvimento da escrita argumentativa. Na primeira fase, as crianças entre os 7 e os 9 anos, nas produções anteriores à intervenção educativa, escrevem textos com

${ }^{1}$ CE2 - Cours élémentaire 2; no «enseignement primaire» do sistema educativo francês, corresponde ao $2 .^{\circ}$ nível do $2 .^{\circ}$ ciclo - apprentissages fondamentaux (alunos com 7-8 anos).

${ }^{2} 5^{\mathrm{e}}-$ corresponde ao $2 .^{\circ}$ ano do $1 .^{\circ}$ ciclo do «enseignement secondaire» (alunos com 12-13 anos). 
frágeis ou inexistentes articulações argumentativas; nas produções livres, os seus textos são mais explicativos do que argumentativos, sendo marcados por uma estratégia de tipo «e depois...». Na segunda fase, os alunos entre os 9 e os 10 anos apresentam as primeiras formas de articulação argumentativa mínima e, nas produções livres, surgem textos argumentativos rudimentares, ainda bastante ancorados em estratégias argumentativas dialogais. Finalmente, a terceira fase, com estudantes entre os 11 e os 13 anos, parece caracterizar-se por uma mestria mínima do texto argumentativo como unidade estruturalmente complexa.

Do conjunto deste trabalho experimental, deve destacar-se o efeito de aceleração que a intervenção educativa teve no grupo dos alunos mais novos. De facto, nos resultados após a intervenção, no grupo de crianças entre os 7 e os 8 anos, observam-se evidências de desenvolvimento da competência argumentativa escrita, havendo desempenhos mais próximos dos perfis dos alunos mais velhos (idem, pp. 36-40). Dominique Brassart, nas suas conclusões, destaca a importância de um desenvolvimento precoce da consciência textual de diferentes géneros, incluindo o argumentativo, mesmo que ainda não tenham sido adquiridas as estruturas linguísticas típicas da argumentação. De facto, a capacidade de manipular metalinguisticamente unidades e frases argumentativas isoladas parece depender de um certo domínio prévio do discurso argumentativo. De forma significativa, a autora questiona ainda a precedência da escrita de narrativas em relação à escrita argumentativa, defendendo o ensino precoce da escrita argumentativa: «Il est donc possible et 'rentable' de travailler avec des jeunes enfants, dès l'école élémentaire, le texte argumentatif écrit - et sans doutes, plus généralement, les divers types de textes» (idem, p. 39).

Pretendendo caracterizar as estratégias de argumentação usadas por crianças entre os 8 e os 12 anos, a frequentar entre a $2 .^{\mathrm{a}}$ e a $4 .^{\mathrm{a}}$ série de escolas brasileiras, maioritariamente públicas, Leal e Morais (2006) desenvolveram um desenho experimental que visava a produção de um texto de natureza argumentativa com o tema «tarefas domésticas», provocando o debate, ou uma aproximação à argumentação polémica, sobre o envolvimento das crianças nas tarefas do dia-adia. As aulas foram observadas e gravadas pelos investigadores e, posteriormente, foram analisados 156 textos produzidos por crianças que, no mínimo, dominavam a escrita alfabética. Para a análise dos textos escritos, foram considerados os seguintes tópicos: (i) quantidade média 
de palavras, (ii) existência de um ponto de vista claro, (iii) apresentação de uma justificação; (iv) fundamentação da justificação e (v) contra-argumentação. Com base nesta análise, procurou-se, de forma mais específica, verificar se as crianças eram capazes de justificar os seus pontos de vista e se manifestavam a capacidade de inserir contra-argumentação nos seus textos. Tal como no estudo de Dominique Brassart, os dados foram tratados estatisticamente e, relativamente aos resultados, destacou-se a perceção da existência de capacidades bastante precoces de escrita argumentativa, por exemplo em configurações textuais que apresentavam claramente um ponto de vista e, pelo menos, uma justificação desse ponto de vista. Ao contrário do que foi evidenciado no estudo francês, não foi possível aos autores brasileiros estabelecerem diferenças estatisticamente significativas entre séries, ou seja, não foi possível identificar um nível de ensino ou uma idade associada à emergência da escrita argumentativa, o que pode apontar para a inexistência de efeitos da escolarização ou, eventualmente, para uma grande variação individual no desenvolvimento da competência de escrita argumentativa. Contudo, atendendo a diferenças de resultados quanto à presença de contra-argumentação nos textos de crianças da $2 .^{\mathrm{a}}$ e da $3 .^{\mathrm{a}}$ série, Leal e Morais (2006, pp. 55-61) identificaram possíveis indícios de efeitos de práticas pedagógicas e de situações de produção de textos argumentativos, aspeto que não foi objeto de investigação no seu estudo, mas deixa em aberto a hipótese de Brassart, segundo a qual o ensino explícito do texto argumentativo tem efeitos na aceleração da competência de escrita argumentativa, pelo menos nos escritores mais novos.

Trabalhos como os de Dominique Brassart e de Telma Leal e Artur Morais destacam a importância de se caracterizarem as fases de desenvolvimento da escrita argumentativa e apresentam resultados que evidenciam a precocidade de capacidades de escrita argumentativa, situando a sua emergência por volta dos 8-9 anos ou mesmo antes, no limiar da escrita compositiva. Estes resultados abrem caminho para a exploração de mais dados, com produções escritas de mais crianças do $1 .^{\circ}$ ciclo em diferentes contextos de aprendizagem. 


\section{Um estudo exploratório sobre capacidades de escrita argumentativa}

O estudo que se apresenta, com as limitações de um estudo exploratório, visa descrever capacidades de escrita argumentativa de crianças portuguesas a frequentar um $4 .^{\circ}$ ano de escolaridade, tendo por referência um contexto curricular que não previa o ensino explícito de texto argumentativo no $1 .^{\circ}$ ciclo de escolaridade. Por outras palavras, as crianças foram colocadas perante a tarefa de escrita de um texto de opinião pela primeira vez no âmbito deste estudo.

Os dados utilizados consistem num subconjunto de textos de opinião de um corpus que foi constituído para o estudo da aquisição e desenvolvimento de estruturas concessivas, em textos de carácter argumentativo, escritos por alunos do $4 .^{\circ}$, do $6 .^{\circ}$ e do $9 .^{\circ}$ ano e por adultos escolarizados (Costa, 2010). No projeto desenvolvido, a fase de diagnóstico do $1 .^{\circ}$ ciclo contava com 24 alunos do $4 .^{\circ}$ ano, com idades compreendidas entre os $9 ; 3.13$ e os $10 ; 2.7^{3}$.

O desenho experimental desta fase de diagnóstico incluiu três testes, um de compreensão oral de texto, outro de produção induzida de frases e outro de produção de texto de opinião, com o tema «experiências em animais». Este tema procurava uma aproximação à argumentação polémica, sendo suscitado o debate sobre as experiências laboratoriais para fins medicinais e para a indústria de cosméticos. Numa abordagem naturalista para a recolha dos dados, os testes foram construídos com formatos próprios de materiais didáticos adequados ao nível de ensino, de forma a serem integrados na planificação do professor titular de turma. No teste de produção de texto, para orientar a fase de planificação e geração de conteúdos, o tema foi introduzido através da atividade de audição de texto, de suporte ao diagnóstico da compreensão oral, e foram dadas algumas instruções no material didático de suporte à tarefa de escrita (anexo 1). Como, com esta turma, não houve outro tipo de intervenção didática sobre texto de opinião, nestas instruções de escrita foram simulados alguns argumentos e contra-argumentos, sendo também dadas indicações explícitas sobre a organização das ideias e extensão do texto, bem como sobre a existência de uma introdução, de um ponto de vista a ser defendido, de argumentos e de uma conclusão persuasiva.

\footnotetext{
${ }^{3}$ 9;3.13 - nove anos, três meses e treze dias / 10;2.7 - dez anos, dois meses e sete dias.
} 
Para um tratamento semiautomatizado dos dados, todos os textos do corpus foram transcritos em ficheiros CHAT, seguindo-se o formato constante no manual de transcrição do sistema CHILDES (MacWhinney, 2000). Com as ferramentas do CLAN, particularmente freq e kwal (para desambiguar conectores em contexto), extraíram-se frequências de uso de diferentes conectores e algumas medidas que serviram para garantir comparabilidade entre os textos do corpus.

O subconjunto de dados de produção textual do $4 .^{\circ}$ ano foi utilizado com um objetivo diferente do de Costa (2010). Trata-se de procurar caracterizar a escrita argumentativa de crianças do $4 .^{\circ}$ ano, tendo em consideração não só elementos da microestrutura textual, como as estruturas sintáticas típicas do discurso argumentativo, entre as quais as concessivas, mas principalmente elementos da macroestrutura. Para a caracterização dos elementos constantes na macroestrutura destes escritos de alunos do 1. ${ }^{\circ}$ ciclo, procedeu-se a uma análise de sequências textuais, considerando-se os tópicos seguintes, comuns a outros estudos sobre argumentação em contexto de escolarização (Brassart, 1990; Leal e Morais; 2006; Marques, 2010):

- enunciação clara de um ponto de vista;

- justificação do ponto de vista;

- presença (e quantidade) de argumentos;

- integração de contra-argumentos;

- formulação de uma conclusão.

Os elementos em análise correspondem a elementos presentes em textos em que se reconheçam sequências dominantemente argumentativas (Adam, 2011). A presença conjunta destes elementos num texto coincidirá com soluções textuais que não se coadunam com a simples acumulação de sequências explicativas. A caracterização do recurso a estes elementos nos textos das crianças deverá evidenciar capacidades e dificuldades em tarefas de escrita argumentativa neste nível de ensino. 


\subsection{Análise de aspetos da macroestrutura}

É importante ter presente que alunos não estavam familiarizados nem com o tipo de texto, nem com o tema ao enfrentarem a tarefa proposta, a escrita de um texto de opinião sobre experiências laboratoriais em animais para se produzirem medicamentos e vacinas e para o fabrico de produtos de higiene e beleza. Porém, da análise dos cinco tópicos antes enunciados, salienta-se o sucesso global na resolução deste problema de escrita, pelo recurso generalizados a elementos prototípicos de uma macroestrutura argumentativa.

Atendendo ao primeiro tópico analisado, a presença de um ponto de vista, em quase todos os textos, num total de 23, aparece de forma clara uma tomada de posição, parecendo ser evidente a capacidade de enunciar um ponto de vista, como, aliás, era solicitado no enunciado da tarefa. Deve notar-se, contudo, que em grande parte dos textos, a fórmula de abertura utilizada não é a mais adequada à introdução de um texto de opinião. Em 19 dos 23 textos com um ponto de vista claro, as aberturas correspondem a formatos de tipo « $\mathrm{Na}$ minha opinião», como em $(6)$, ou «(Eu) acho (que)», como em (7).

(6) *FA4: Na minha opinião os animais não devem ser usados como cobaias [...] $(10 ; 2.07)^{4}$.

(7) *FC4: Eu acho que as pessoas não devem fazer mal aos animais [...] (9;5.01).

A constatação de que as crianças ainda não usam aberturas de texto de opinião mais adequadas a um texto autónomo, optando por um formato típico de resposta a uma pergunta ou pedido de opinião em contexto de pergunta-resposta, é coincidente com os resultados a que chegaram Leal e Morais (2006). Esta característica da escrita de textos de opinião pode ser explicada não tanto com a incapacidade das crianças para se posicionarem face a uma situação problemática ou a uma polémica, mas com o tipo de tarefas escolares de escrita com que estão mais familiarizadas.

\footnotetext{
${ }^{4} \mathrm{Na}$ transcrição de exemplos dos textos, mantém-se a codificação do corpus de Costa (2010) e apresenta-se a indicação da idade. Assim, a notação *XX4 corresponde à codificação dos sujeitos do $4 .^{\circ}$ ano; com [\% spe] assinalam-se erros de ortografia e de pontuação; com [*] assinalamse erros morfossintáticos.
} 
No que diz respeito à capacidade de introduzir argumentos ou, de forma mais incipiente, apresentar razões para defender o ponto de vista enunciado, também a maioria dos textos mostra que os alunos de 4 . $^{\circ}$ ano já são capazes de o fazer. De entre o total dos 24 textos, apenas três não incluem qualquer argumento e o que, de facto, deve ser destacado é que, em 19 textos, há mais de dois argumentos, ou seja, os alunos não se limitam a reproduzir os argumentos sugeridos no enunciado da tarefa (anexo 1). Na análise da presença e da quantidade de argumentos, poder-se-ia dar o caso de os jovens escritores adotarem uma das perspetivas assumidas nos balões de pensamento das personagens do enunciado, limitando-se a colar as razões apresentadas em defesa de cada ponto de vista. No entanto, essa possibilidade, que invalidaria os resultados, não se verificou, uma vez que, na maioria dos textos, se encontram pelo menos três argumentos, sendo maioritariamente originais, ainda que formulados de modo bastante simples, aduzindo razões da experiência pessoal, e com uma estrutura textual simplificada, como se exemplifica em (8).

(8) *FB4: Além disso nós precisamos dos animais selvagens e dos animais domésticos, vouvos dar duas razões porque [*] precisamos dos animais.

*FB4: Um.

*FB4: Os animais domésticos fazem-nos companhia [\%spe: 0;].

*FB4: Dois.

*FB4: E os animais selvagens dão-nos alimentos. $(10 ; 1.11)$

Ainda quanto à estrutura argumentativa, salienta-se a existência de seis textos em que se consegue manter uma estratégia incipiente de dupla orientação argumentativa. Esta hipótese de estruturação do texto de opinião é sugerida pelo terceiro balão de pensamento do enunciado, mas, uma vez mais, não se verifica qualquer colagem à proposta do enunciado, havendo evidências de que alguns alunos conseguem construir os seus textos apresentando razões favoráveis e desfavoráveis aos pontos de vista em conflito. Em (9), apresenta-se uma sequência exemplificativa desta solução de escrita. 
(9) *FC4: Eu também acho que as pessoas não deviam fazer experiências com os animais que provocassem [\%spe: provocasem] sofrimento aos animais [\%spe: 0,] mas eu acho que é [*] importante $\left.{ }^{*}\right]$ as descobertas das curas para as doenças do Homem para os animais e dos animais para o Homem. $(9 ; 5.01)$

Note-se, como se referirá em 4.2., que a adoção desta perspetiva de estruturação argumentativa implica o recuso a conectores de contraste, como o «mas» que se encontra no exemplo (9).

Além da presença de argumentos e da quantidade de argumentos, outro tópico considerado para análise consistiu na apresentação de justificações do ponto de vista adotado. Embora este elemento não fosse indicado nas instruções do enunciado, à semelhança dos tópicos anteriores, a maioria dos textos, num total de 19, integra uma justificação para o ponto de vista enunciado, fazendo-o de forma explícita com o recurso ao conector causal «porque», como se ilustra em (10).

(10) *MA4: $\quad$ Na minha opinião estes animais não são muito bem apropriados para as experiências [\%spe: experiencias], [\%spe: *.] porque [\%spe: Porque] os animais não são a mesma coisa que os seres humanos. $(9 ; 6.20)$

Pelo contrário, relativamente à necessidade de uma conclusão persuasiva, as instruções do enunciado são claras, indicando que «no final do texto, tenta mostrar que tu é que tens razão» (anexo 1). Todavia, em mais de metade dos textos são evidentes as dificuldades em estruturar uma conclusão adequada ao texto, com ou sem elementos que pudessem ser considerados persuasivos. Da análise efetuada, apenas 11 textos incluem uma conclusão adequada, o que é um resultado consistente com características descritas em outros estudos sobre o desenvolvimento da escrita argumentativa (Brassart, 1990; Leal e Morais, 2006). De igual modo, também se confirmou a dificuldade em enunciar contra-argumentos, havendo apenas oito textos que recorrem a esta estratégia. 
No quadro 1, sintetizam-se os resultados da análise dos elementos da macroestrutura dos 24 textos de opinião de alunos do $4^{\circ}$ ano.

\begin{tabular}{|l|c|c|}
\hline $\begin{array}{l}\text { Elementos da estrutura } \\
\text { textual }\end{array}$ & $\begin{array}{l}\text { Total de } \\
\text { textos }\end{array}$ & Percentagens \\
\hline Ponto de vista & 23 & $95,8 \%$ \\
\hline Justificação do ponto de vista & 19 & $79,2 \%$ \\
\hline Argumentos & 21 & $87,5 \%$ \\
\hline Contra-argumentos & $\mathbf{8}$ & $\mathbf{3 3 , 3 \%}$ \\
\hline Conclusão & $\mathbf{1 1}$ & $\mathbf{4 5 , 8 \%}$ \\
\hline
\end{tabular}

Quadro 1: Elementos da macroestrutura

Em consonância com uma das conclusões de Leal e Morais (2006), a de que é possível inferir a existência de variação individual nas competências de escrita argumentativa entre estes escritores dos primeiros anos de escolaridade pouco expostos ao ensino formal da escrita, deve igualmente registar-se a diversidade de soluções face à tarefa proposta. Assim, devem ser tidos em consideração os seis casos de alunos que, apesar das instruções orientadoras do enunciado, não foram capazes de dominar os padrões mínimos de escrita argumentativa e, na totalidade do texto ou no final do seu escrito, recorreram às convenções típicas do relato e da narrativa. Disto é exemplo o texto de MB4, um aluno de 9 anos, que até consegue usar uma abertura aceitável como enunciação de ponto de vista, a qual se transcreve em (11):

(11) *MB4: Os humanos não devem fazer sofrer os animais, nós [\%spe: nos] temos direito à [\%spe: á] vida [\%spe: 0,] mas não só nós [\%spe: 0,] os animais também. (9;3.13) 
Contudo, a sua escrita parece não aguentar uma textualização em formato de argumentação ou de explicação, mudando abruptamente para o registo típico do relato, como se verifica em (12).

(12) *MB4: A Política proibiu [\%spe: puribiu] experimentarem [\%spe: expermentarem] produtos [\%spe: prudotos] nos animais selvagens e domésticos [\%spe: dómesticos].

*MB4: Passado [*] milhões de anos nunca mais se viu [\%spe: seviu] químicos.

Mais ilustrativa ainda desta fuga ao modelo de composição argumentativa é a tentativa de conclusão, em (13), num registo típico de um final feliz de uma história.

(14) *MB4:Para concluir a $\mathrm{xx}$ ninguém [\%spe: nínguem] sabia fazer produtos [\%spe: prudutos] químicos.

*MB4: E por isso o mundo animal ficou feliz.

Este exemplo do texto de MB4 parece ilustrar a incapacidade de alguns escritores menos proficientes ativarem um modelo de transformação de conhecimento, mantendo a resolução do seu problema de escrita dependente de estratégias típicas de um modelo simples de relato de conhecimento (Scardamalia e Bereirter, 1987a, 1987b). Esta fuga para o modo de relato ou de narrativa pode ser um dos indicadores de que a mestria deste género precede a iniciação a géneros mais complexos, como o argumentativo. Pelo menos para alguns alunos, este parece ser o caminho mais natural para enfrentar uma tarefa de escrita, independentemente das instruções da tarefa.

De qualquer forma, na análise dos 24 textos, a maioria dos alunos conseguiu dominar genericamente os padrões de escrita argumentativa, ainda que de forma incipiente, como parece ser típico na escrita compositiva desta fase (Brassart, 1990; Leal e Morais, 2006). O texto de FA4 ilustra o facto de que muitos alunos, apesar de não o terem aprendido de forma explícita, são capazes de adotar um registo adequado a uma tarefa de escrita de texto de opinião. Este texto de 
uma aluna de 10 anos apresenta a enunciação do ponto de vista que vai defender e a sua justificação (14).

(14) *FA4: Na minha opinião os animais não devem ser usados como cobaias, [\%spe: *.] porque [\%spe: Porque] os animais são seres vivos que os humanos usam sem pensar no que podia doer se estivessem [\%spe: estivesem] no lugar deles. (10;2.07)

O texto de FA4 integra vários argumentos, como por exemplo (15), e uma conclusão correspondente à formulação de uma intenção persuasiva, transcrita em (16).

(15) *FA4: Oapesar+de serem irracionais [\%spe: inrracionais] [\%spe: 0,] devem ter um dono que goste deles (domésticos).

(16) *FA4: Não se esqueçam [\%spe: 0:] tratem bem os animais.

Com estes excertos de um texto do $4 .^{\circ}$ ano, exemplificam-se as conclusões a que os estudos mencionados chegaram: embora a escrita de textos de carácter argumentativo, como os textos de opinião, seja mais difícil de dominar precocemente, é uma capacidade em desenvolvimento que não pode ser ignorada pelos currículos escolares.

\subsection{Análise de aspetos da microestrutura}

O facto de algumas estruturas linguísticas serem adquiridas mais tardiamente, como será o caso de estruturas tipicamente usadas na argumentação, como as contrastivas, as causais ou as condicionais (Bowerman, 1986; Costa, 2010; Diessel, 2004; Evers-Vermeul, 2005), pode ser usado como argumento favorável a uma introdução mais tardia dos textos argumentativos no currículo. Neste caso, o desenvolvimento linguístico funcionaria como precursor dos usos de língua. Ora, vários estudos na área do desenvolvimento linguístico tardio, que normalmente acompanha o percurso de escolarização, mostram que há uma estreita articulação entre a 
exposição a ambientes linguísticos diferentes dos familiares, como os escolares, e a promoção de uma «literacia linguística» (Berman, 2004), ou seja, de uma mestria linguística que garante o acesso a diferentes registos de língua. Neste caso, poder-se-á entender a introdução precoce de tarefas escolares que envolvam a compreensão e a produção de textos de carácter argumentativo como uma estratégia promotora do desenvolvimento de estruturas linguísticas menos familiares.

$\mathrm{Na}$ análise de elementos da microestrutura, foram tidas em consideração estruturas sintáticas prototípicas do discurso argumentativo, como frases que expressam nexos contrastivos (coordenadas adversativas e subordinadas concessivas), frases que expressam nexos causais/explicativos (coordenadas explicativas e subordinadas causais), bem como subordinadas condicionais. $\mathrm{Na}$ análise destas estruturas, atendeu-se particularmente à frequência de uso de conectores, bem como ao nexo semântico operado.

Entre a minoria de textos em que se usa uma estratégia aproximada da dupla orientação argumentativa e nos poucos textos em que se observa a presença de contra-argumentos, é possível detetar o recurso a estruturas sintáticas com nexos contrastivos, associadas a funções textuais específicas da contraposição de argumentos. Em apenas três destes textos se recorre a estruturas contrastivas de subordinação concessiva para estruturar um ponto de vista com dupla orientação argumentativa (17) e para contra-argumentar (18).

(17) *MJ4: A exploração dos animais é cruel, embora descubra curas para humanos. (9; 11.13)

(18) *FA4: Apesar+de serem usados para medicamentos, cosméticos e às vezes para roupa [\%spe: 0,] são seres que Deus criou e não devem ser destruídos. (10;2.07)

Sendo apenas três as crianças que recorrem espontaneamente a conectores concessivos ${ }^{5}$, estes casos não são representativos da enunciação de contraste usada na globalidade dos textos de

\footnotetext{
${ }^{5}$ Nos 24 textos de $4 .^{\circ}$ ano, encontram-se apenas cinco conectores conjuncionais concessivos (três «apesar de» e dois «embora»), usados em três textos.
} 
opinião analisados: para expressar ideias em contraste as crianças usam quase exclusivamente a coordenação adversativa com «mas», como em (19).

(19) *FC4: Eu também acho que as pessoas não deviam fazer experiências com os animais que provocassem [\%spe: provocasem] sofrimento aos animais [\%spe: 0,] mas eu acho que é [*] importante [*] as descobertas das curas para as doenças do Homem para os animais e dos animais para o Homem. $(9 ; 5.01)$

A figura 1 ilustra a frequência de uso de conectores conjuncionais contrastivos, salientandose a clivagem entre o recurso a subordinação concessiva e a coordenação adversativa.

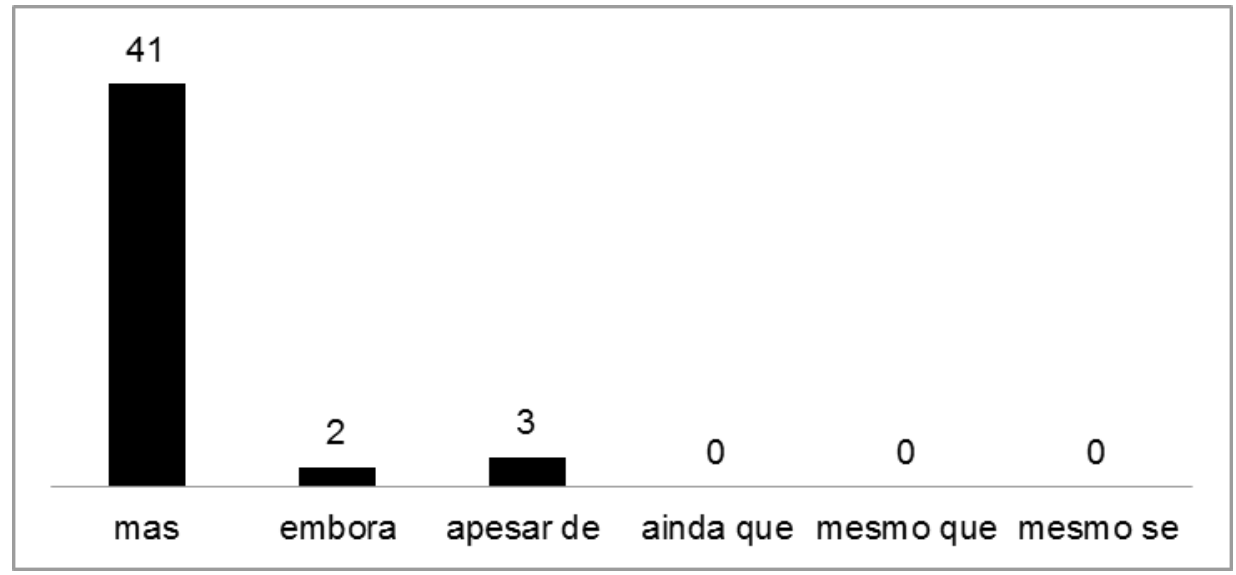

Figura 1: Produção de conectores conjuncionais contrastivos

Note-se, porém, que nos testes de compreensão oral e de produção induzida de frases, em Costa (2010, pp. 156-169), os mesmos jovens escritores mostraram ser capazes de compreender e de produzir, em exercícios controlados de manipulação de estruturas, mais conectores contrastivos do que os que são capazes de mobilizar espontaneamente em situação de produção escrita.

Relativamente ao recurso a nexos causais/explicativos, estes surgem fundamentalmente com a função de estruturar as justificações dos pontos de vista. Como se referiu em 4.1., as crianças adotaram, muito frequentemente, um formato típico de respostas a pedidos de opinião, seguido de 
uma justificação introduzida por «porque», como se ilustra em (20); noutras sequências, as explicações ou causas são também maioritariamente expressas pelo mesmo conector.

(20) *FD4: Eu acho que nunca devemos fazer mal aos animais porque eles são nossos amigos. $(9 ; 11.02)$

Considerando a totalidade dos textos, em 67\% (em 16 textos), as crianças mostram ser capazes de recorrer a estruturas causais na estruturação dos seus textos de opinião. Para expressar nexos causais/explicativos, usam quase exclusivamente «porque», como se pode verificar na figura 2.

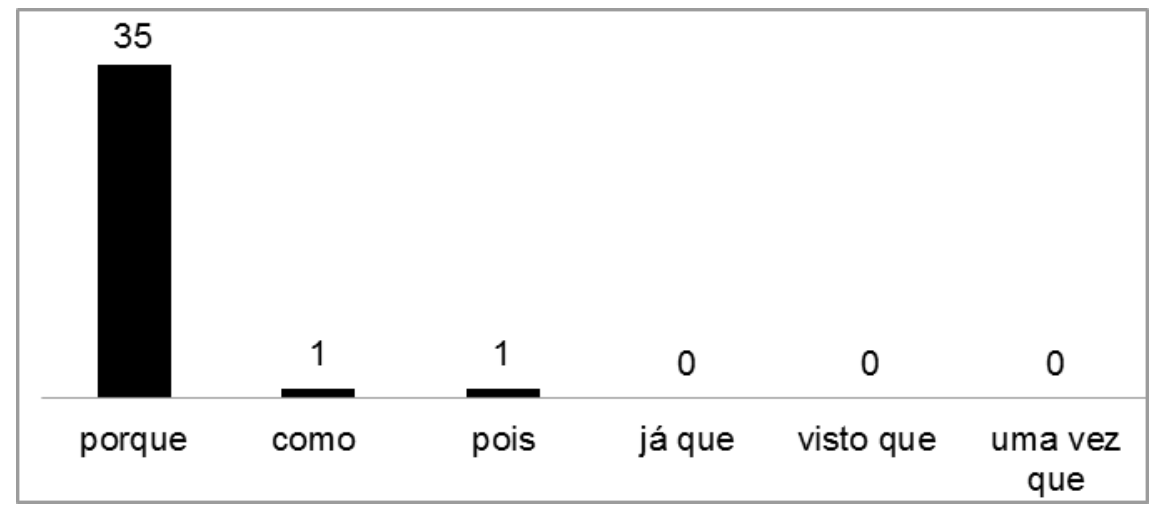

Figura 2: Produção de conectores conjuncionais causais/explicativos

E, nestes textos de alunos do $4 .^{\circ}$ ano, é igualmente possível verificar que as estruturas condicionais aparecem ao serviço da construção da argumentação, como se atesta em (21).

(21) *FI4: Se as pessoas continuarem as testar os produtos em animais, os pobrezinhos podem ficar em vias de extinção ou até desaparecer [\%spe: dezaparecer]. $(9 ; 10.12)$

Se o uso de outros conectores além de «mas» e de «porque» é pouco expressivo, no paradigma dos conectores condicionais, as crianças só recorrem ao «se», não havendo qualquer outra forma de expressão de condição. Em comparação com «mas» e com «porque», o conector «se» é menos usado, havendo apenas 15 ocorrências em oito dos 24 textos. 
Da análise de estruturas sintáticas que garantem uma estrutura argumentativa, pôde verificarse que as crianças são capazes de expressar nexos contrastivos, usando abundantemente «mas» (41 em 24 textos), bem como nexos causais/explicativos, com «porque», e condicionais, com «se». A ausência de um repertório mais alargado de conectores nesta tarefa de escrita, ainda assim, merece alguma reflexão, visto que estes três conectores emergem relativamente cedo no discurso oral. O estudo de Costa, Alexandre, Santos e Soares (2008) identifica estes mesmos conectores em produções a partir dos dois anos, de acordo com a escala em (22).

(22) Escala de emergência de conectores

$\operatorname{mas}(2 ; 2.8)>$ porque $(2 ; 3.22)>$ se $(2 ; 5.23)$

A constatação de que os alunos, para resolverem uma tarefa de escrita argumentativa, recorrem às mesmas estruturas que usam no discurso oral desde os dois anos conduz à reflexão sobre o efeito do ensino intencional do texto argumentativo como promotor de desenvolvimento linguístico. Se estas estruturas já estão adquiridas, tarefas de escrita de texto de opinião que incluam a revisão textual centrada em exercícios de substituição de conectores por outros do mesmo paradigma semântico podem estimular o alargamento do conhecimento lexical de conjunções e, consequentemente, propiciar o desenvolvimento sintático. Esta hipótese encontra fundamento na ideia de que o conhecimento de estruturas linguísticas não precede o domínio de diferentes géneros discursivos, havendo antes uma interação entre conhecimento e uso: o contacto com diferentes géneros conduz à necessidade de se usarem estruturas linguísticas menos frequentes (Nippold, 2004). Antecipar curricularmente o ensino do texto de carácter argumentativo será, neste sentido, uma medida que beneficiará, além do mais, o desenvolvimento de uma «literacia linguística» (Berman, 2004).

\section{Considerações finais}

A natureza exploratória do estudo apresentado limita, necessariamente, a formulação de conclusões definitivas quer sobre uma eventual datação da emergência da escrita argumentativa, 
na fase de iniciação à escrita compositiva, quer sobre as características desta escrita nos primeiros anos de escolaridade. Apresentam-se, ainda assim, algumas considerações sobre o tema.

Como ficou exposto na análise de elementos da microestrutura textual, em concreto na caraterização das estruturas sintáticas necessárias a uma estrutura argumentativa, na produção escrita os alunos usam os conectores disponíveis na sua gramática oral, argumentando com recursos linguísticos básicos. Por outras palavras, usam os mesmos conectores que usam na oralidade desde os dois anos, embora, em testes de compreensão oral e de produção induzida de frases, manifestem ter em estabilização o conhecimento de um repertório mais alargado de possibilidades expressivas, que não conseguem mobilizar ainda para situações de escrita.

No que diz respeito aos elementos de uma macroestrutura de texto de opinião, uma elevada percentagem de textos (mais de 75\%) inclui (i) a enunciação de um ponto de vista, (ii) a sua justificação e (iii) mais de dois argumentos, o que parece evidenciar que a capacidade de produção de escrita argumentativa está em desenvolvimento, apesar da inexistência de orientações curriculares para o ensino explícito da escrita argumentativa. As fragilidades da escrita argumentativa precoce situam-se (i) na produção de uma conclusão e (ii) na integração de contra-argumentos (ou do ponto de vista do outro). Estas observações são consensuais com os resultados de outros estudos que se dedicam a explicar as características da escrita argumentativa em diferentes contextos escolares (Brassart, 1990; Leal e Morais, 2006).

Os resultados apresentados permitem defender um ponto de vista favorável à intervenção educativa precoce na escrita de textos predominantemente argumentativos. Os resultados do estudo apresentado sugerem uma resposta positiva à questão orientadora da pesquisa: deve promover-se a escrita de textos de opinião, e de outros géneros textuais, na fase de emergência da escrita compositiva. Se considerarmos a meta curricular transcrita em (5), para o $6 .^{\circ}$ ano do $2 .^{\circ}$ ciclo, verificamos que os textos analisados, escritos por alunos do 4. ${ }^{\circ}$ ano, já evidenciam globalmente a capacidade de «escrever textos com a tomada de uma posição, a apresentação de, pelo menos, três razões que a justifiquem, com uma explicação dessas razões» (DGE, 2015, p. 71), falhando a formulação de «uma conclusão coerente». Estudos como os de Brassart (1990) e de Leal e Morais (2006), bem como a análise dos elementos da macroestrutura dos textos de opinião de $4 .^{\circ}$ ano parecem indicar que haverá benefícios em promover a escrita de diferentes 
géneros desde o início, havendo percursos de desenvolvimento específicos associados ao texto argumentativo.

Quanto à questão enunciada em (3), os resultados da análise dos elementos da microestrutura parecem indiciar que é importante pôr os alunos a escrever textos de opinião de forma a criar condições linguísticas estimulantes para o alargamento lexical, no uso de conectores, e consequentemente para o desenvolvimento da fluência sintática, que, por sua vez vão garantir o desenvolvimento da competência textual. Este ponto de vista contrasta enormemente com as condições de ensino da escrita estabelecidas pelo atual Programa e Metas, de onde se excluiu completamente a possibilidade de escrever texto de opinião antes do $2 .^{\circ}$ ciclo. Que razões existem para documentos orientadores atualizados continuarem a omitir o ensino intencional da escrita argumentativa?

Num outro sentido, o da investigação sobre a emergência e o desenvolvimento da escrita argumentativa, o aprofundamento deste estudo exploratório terá de passar, naturalmente, pela análise de textos de crianças ainda mais novas, no primeiro ou no segundo ano de aprendizagem, logo no início da escrita compositiva, e pela consideração de um número superior de textos. Por agora, parece adequado concluir com as palavras de uma das jovens escritoras do $1 .^{\circ}$ ciclo: «desculpe, mas não sei mais».

\begin{tabular}{l}
\hline Lesculhe mas mac sei mail \\
\hline Tim \\
\hline
\end{tabular}




\section{Referências}

Adam, Jean-Michel (2011) Textes: Types et Prototypes [1992]. 3. a edição. Paris: Armand Colin.

Barbeiro, Luís Filipe \& Maria Luísa Álvares Pereira (2007) O Ensino da Escrita: A Dimensão Textual. Lisboa: ME.DGIDC.PNEP.

Berman, Ruth (2004) Between emergence and mastery. The long development route of language acquisition. In Ruth Berman (ed.). Language development across childhood and adolescence. Amsterdam, Philadelphia: John Benjamins, pp. 9-34.

Bowerman, Melissa (1986) First steps in acquiring conditionals. In Elizabeth Traugott et al. (orgs.). On Conditionals. Cambridge: Cambridge University Press, 285-307.

Brassart, Dominique (1990) Le développement des capacités discursives chez l'enfant de 8 à 12 ans. Revue Française de Pédagogie, n. ${ }^{\circ}$ 90, pp. 31-41.

Costa, Ana Luísa (2010) Estruturas contrastivas: desenvolvimento do conhecimento explícito $e$ da competência de escrita, dissertação de doutoramento apresentada à Universidade de Lisboa.

(2015). Gramática \& escrita: o caso das contrastivas. Revista Palavras, n. ${ }^{\circ}$ 46-47, pp. 72-89.

Costa, Ana, Nélia Alexandre, Ana Lúcia Santos \& Nuno Soares (2008) Efeitos de modelização no input: o caso da aquisição de conectores. In Ana Lúcia Santos \& Sónia Frota (orgs.) Textos Selecionados do XXIII Encontro da Associação Portuguesa de Linguística. Lisboa: APL, Colibri, pp. 131-142.

DEB (2001) Currículo Nacional do Ensino Básico - Competências Essenciais. Lisboa: DEB.ME. DGE (2012) Metas curriculares de Português. Ensino básico. Lisboa: MEC.

DGE (2015) Programa e metas curriculares de Português do ensino básico. Lisboa: DGE. MEC. DGEBS (1991) Programa de Língua Portuguesa - Plano de Organização do Ensino/Aprendizagem - Ensino Básico - 3. ${ }^{\circ}$ Ciclo, vol. I e II. Lisboa: DGEBS.ME.

DGIDC (2009) Programas de Português do Ensino Básico. Lisboa: DGIDC.ME. 
Diessel, Holger (2004) The acquisition of complex sentences. Cambridge: Cambridge U.P.

Evers-Vermeul, Jaqueline (2005) The development of dutch connectives: change and acquisition as windows on form-function Relations. Utrecht: LOT.

Ferreiro, Emilia \& Ana Teberosky (2009) Psicogênese da língua escrita. [1979]. Porto Alegre:

Artmed.

Flamenco García (1999) Las Construcciones Concesivas y Adversativas. In Violeta Demonte y Ignacio Bosque (dirs.) Gramática Descriptiva de la Lengua Española - 3 - Entre la Oración y el Discurso. Madrid: Espasa-Calpe, pp. 3805-3878.

Grabe, William \& Robert Kaplan (1996) Theory and Practice of Writing. Londres e Nova Iorque: Longman.

Hayes, John \& Linda Flower (1980) Identifying the organization of writing processes In Lee W. Gregg \& Erwin R. Steinberg (eds.) Cognitive Processes in Writing. Hillsdale, New Jersey: Lawrence Erlbaum Associates.

Leal, Telma Ferraz \& Artur Gomes de Morais (2006) A argumentação em textos escritos: a criança e a escola. Belo Horizonte: Autêntica.

Marques, Carla (2010) A argumentação oral formal em contexto escolar, dissertação de doutoramento apresentada à Universidade de Aveiro.

Martins, Margarida Alves \& Ivone Niza (1998) Psicologia da aprendizagem da linguagem escrita. Lisboa: Universidade Aberta.

MacWhinney, Brian (2000) The CHILDES Project: Tools for Analyzing Talk. 3. ${ }^{a}$ edição. Mahwah, NJ: Lawrence Erlbaum Associates.

Menyuk, Paula \& Maria Estela Brisk (2005) Language development and education. Children with varying language experiences. New York: Palgrave. MacMillan.

Nicholls, John et al. (1989) Beginning Writing. Philadelphia: Open University Press.

Nippold, Marilyn (2004) Research on Later Language Development. In Ruth Berman Ruth (ed.) Language Development Across Childhood and Adolescence. Amsterdam, Philadelphia: John Benjamins, 1-8. 
Scardamalia, Marlene \& Carl Bereiter (1987a) The psychology of written composition. Nova Iorque e Londres: Routledge.

Scardamalia, Marlene \& Carl Bereiter (1987b) Knowledge telling and knowledge transforming in written composition In Rosenberg, Sheldon (ed.) Advances in applied psycholinguistics. Vol. 2. Reading, writing and language learning. New York: Cambridge University Press.

Sim-Sim, Inês, Inês Duarte e Maria José Ferraz (1997) A Língua Materna na Educação Básica. Lisboa: DEB.ME.

Sim-Sim, Inês (2007) O ensino da leitura. A compreensão de textos. Lisboa: PNEP. DGIDC. ME.

(2009) O ensino da leitura. A decifração. Lisboa: PNEP. DGIDC. ME. 


\section{Anexos}

Anexo 1 - Teste de Produção de Texto (PT) (Costa, 2010)

\section{Experiências em animais}

Como sabes, antes de nos serem vendidos, vários produtos de higiene e beleza são experimentados em animais, causando-lhes doenças e até a morte. As experiências em animais também servem para fabricar medicamentos, essenciais para o bem-estar dos homens.

O sofrimento provocado nos animais é um assunto complicado e nem todas as pessoas partilham da mesma opinião, como podes ler a seguir...

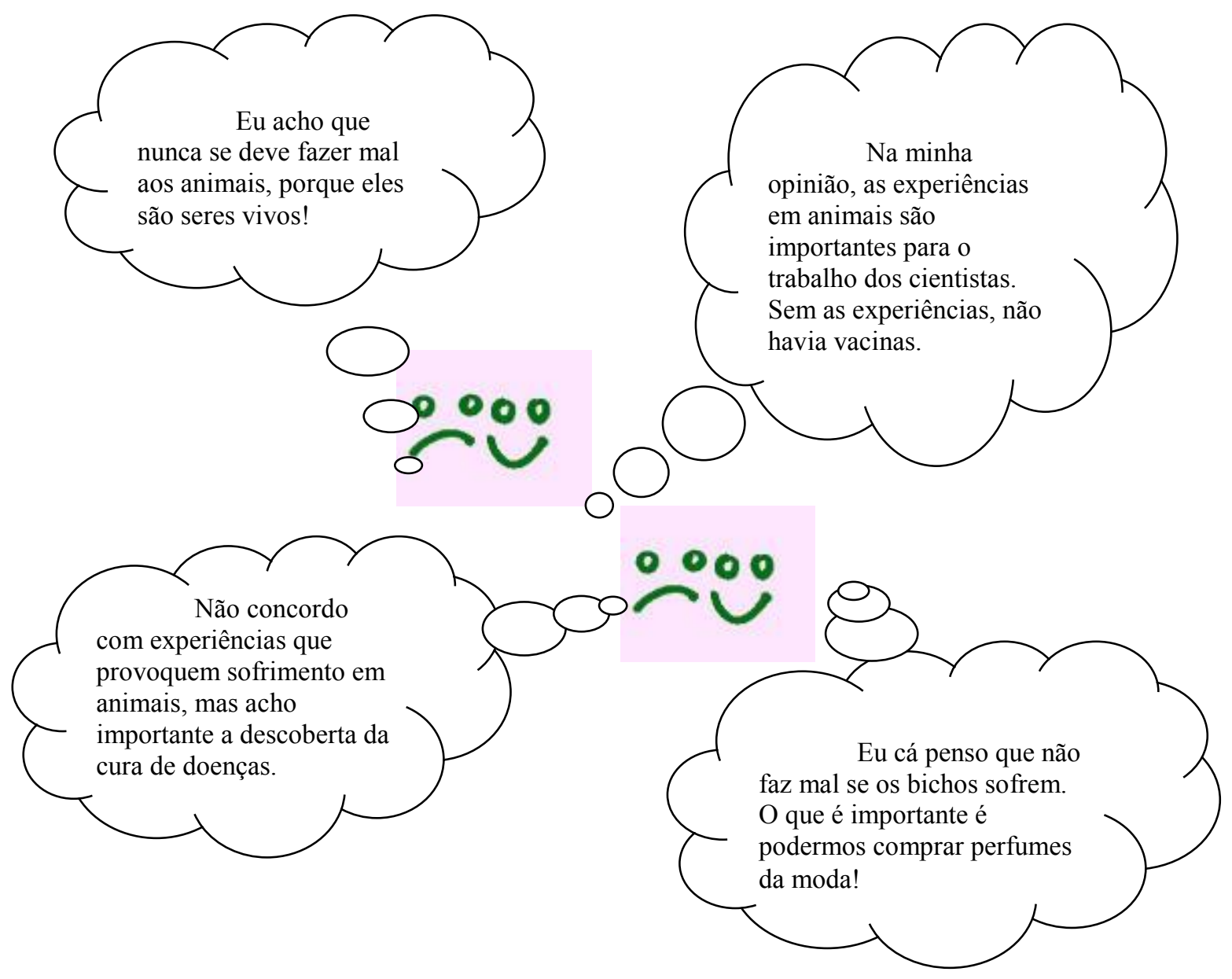


Escreve um texto em que defendas a tua opinião sobre este assunto:

$\checkmark$ Antes de começares a escrever, organiza as tuas ideias;

$\checkmark$ Não te esqueças de fazer uma introdução, apresentando aos teus leitores o assunto que vais tratar;

$\checkmark$ Apresenta bons argumentos para defenderes o teu ponto de vista;

$\checkmark$ No final do texto, tenta mostrar que tu é que tens razão;

$\checkmark$ Escreve pelo menos 20 linhas. 